STUDI

FRANCESI

\section{Studi Francesi}

Rivista quadrimestrale fondata da Franco Simone

144 (XLVIII | III) | 2004

Varia - fasc. III - settembre-dicembre 2004

\title{
Stendhal sous l'œil de la presse contemporaine (1817-1843), textes réunis et publiés par Victor del Litto
}

Michel Arrous

\section{(2) OpenEdition}

Journals

Édition électronique

URL : https://journals.openedition.org/studifrancesi/37878

DOI : 10.4000/studifrancesi.37878

ISSN : 2421-5856

Éditeur

Rosenberg \& Sellier

Édition imprimée

Date de publication : 15 décembre 2004

Pagination : 625-626

ISSN : 0039-2944

\section{Référence électronique}

Michel Arrous, "Stendhal sous l'œil de la presse contemporaine (1877-1843), textes réunis et publiés par Victor del Litto ", Studi Francesi [En ligne], 144 (XLVIII | III) | 2004, mis en ligne le 30 novembre 2015, consulté le 08 mai 2021. URL : http://journals.openedition.org/studifrancesi/37878 ; DOI : https:// doi.org/10.4000/studifrancesi.37878

Ce document a été généré automatiquement le 8 mai 2021.

\section{cc) $(1) \odot$}

Studi Francesi è distribuita con Licenza Creative Commons Attribuzione - Non commerciale - Non opere derivate 4.0 Internazionale. 


\title{
Stendhal sous l'œil de la presse contemporaine (1817-1843), textes réunis et publiés par Victor del Litto
}

\author{
Michel Arrous
}

\section{RÉFÉRENCE}

AA. VV., Stendhal sous l'œil de la presse contemporaine (1817-1843), textes réunis et publiés par Victor del LITTO, Paris, Honoré Champion, 2001, pp. 925.

Prudemment, V. Del Litto nous rappelle qu'il faut bannir le mot «définitif» quand on s'attelle à l'établissement d'une bibliographie. Toujours plein d'ardeur, le maître a entrepris de publier tout ce qui a paru sur Stendhal dans la presse périodique de 1817 à 1900. Tâche démesurée? Rien n'est moins sûr, même si tout stendhalien chevronné se fait fort de ramener au jour un article oublié.

2 L'exemple des «petits journaux», si appréciés de Stendhal sous la Restauration, suffira: qui peut prétendre les avoir tous lus? Il y a donc encore d'intéressantes découvertes à faire... Quant au stendhalien vétilleux - il en existe - il déplorera l'absence du compte rendu des Promenades dans Rome dans le Courrier des Tribunaux (21 octobre 1829), détail dérisoire quand on voit que la section consacrée à ce récit de voyage compte douze articles ou que La Pandore est peu citée. De même pour l'article sur La Chartreuse paru dans l'«inarrivable» Charivari du 23 avril 1839. Broutilles pour qui peut désormais lire des articles peu connus ou difficiles d'accès comme ceux de la Gazetta di Milano, du très fameux Carpani, de l'Edinburgh Review, qui épingla Stendhal pour n'avoir pas cité ses sources, à savoir elle-même, de l'Antologia (cinq articles) ou du Globe. Soit, à titre d'exemple, 57 pages pour Le Rouge, 97 pour les Mémoires d'un touriste et 79 pour La Chartreuse. Notons que V. Del Litto a donné les textes anglais et italiens accompagnés de leur traduction. Relevons aussi une curiosité: la publication par Le Voleur (15 novembre 
1839) d'un extrait de L'Abbesse de Castro sous le titre «Chroniques italiennes», ce qui prouve que R.Colomb n'a pas inventé l'appellation controversée.

3 Après Paupe et Cordier (1914) et le Stendhal. Mémoire de la critique préfacé par M.Crouzet (1996), le lecteur dispose, avec ce premier volume, du répertoire le plus complet consacré à la réception de Stendhal. On attend impatiemment la suite du dossier, mais on a déjà la preuve que Stendhal ne fut pas méconnu de ses contemporains. 